\title{
Regio- and Stereoselective Cyclopolymerization of 1,2:5,6-Dianhydro-3,4-di- $O$-methyl-D-glucitol Leading to Polymers with 2,5-Anhydro-3,4-di- $O$-methyl-D-mannitol and/or -L-iditol Units
}

\author{
Toshifumi Satoh, ${ }^{\dagger}$ Takeshi Hatakeyama, Satoshi Umeda, Kazuaki Yokota,${ }^{\dagger \dagger}$ and Toyoji KaKuchi ${ }^{*}, \dagger+$ \\ Division of Molecular Chemistry, Graduate School of Engineering, Hokkaido University, \\ Sapporo 060, Japan \\ * Division of Bioscience, Graduate School of Environmental Earth Science, Hokkaido University, \\ Sapporo 060, Japan
}

(Received November 6, 1995)

\begin{abstract}
The cyclopolymerization of 1,2:5,6-dianhydro-3,4-di-O-methyl-D-glucitol was carried out using cationic and anionic catalysts. The polymerizations proceeded homogeneously up to high conversion and gave linear polymers without formation of gel. For the cationic cyclopolymerizations using $\mathrm{BF}_{3} \cdot \mathrm{OEt}_{2}$ and $\mathrm{SnCl}_{4}$, the resulting polymer was confirmed to have the constitutional unit mainly of 2,5 -anhydro-3,4-di- $O$-methyl-D-mannitol by comparing its ${ }^{13} \mathrm{C}$ NMR spectrum with that of 2,5-anhydro-1,3,4,6-tetra- $O$-methyl-D-mannitol. For anionic cyclopolymerization using $t$-BuOK, the obtained polymer consisted of two cyclic repeating units, 2,5-anhydro-3,4-di- $O$-methyl-D-mannitol and 2,5-anhydro-3,4-di- $O$-methyl-L-iditol. For the regio- and stereoselective polymerizations, intra- and intermolecular reactions introduced $\alpha$ - and $\beta$-scissions of the epoxides with inversion and retention of the configuration at the $\alpha$-carbon, respectively.

KEY WORDS Cationic Polymerization / Anionic Polymerization / Cyclopolymerization / D-Glucitol / D-Mannitol / L-Iditol / Five-membered Ring / Regioselective / Stereoselective / Baldwin Rule /
\end{abstract}

The synthesis of polysaccharide with the same or mimetic structure as that of the natural product was studied for biochemical, biomedical, and other applications. The ring-opening polymerization of anhydro sugars is established as a strategy for producing highly stereoregular polycarbohydrates. ${ }^{1-11}$ The cyclopolymerization of 1,2:5,6-dianhydrohexitol is also a useful method. ${ }^{12-19}$ Both 1,2:5,6-dianhydro-3,4-di- $O$-methylD-mannitol (1) and -L-iditol (2) were cyclopolymerized using boron trifluoride etherate $\left(\mathrm{BF}_{3} \cdot \mathrm{OEt}_{2}\right)$ to produce a polymer consisting mainly of 2,5-anhydro-3,4-di- $O$ methyl-D-glucitol as the constitutional cyclic unit. ${ }^{15}$ The anionic cyclopolymerization of $\mathbf{1}$ using potassium tert-butoxide $(t$-BuOK) was highly regio- and stereoselective and the polymer obtained had a stereospecific structure, i.e., $(1 \rightarrow 6)-2,5$-anhydro-3,4-di- $O$-methyl-Dglucitol (3). ${ }^{16,17} \mathrm{D}-\mathrm{Mannitol}$ and L-iditol have $\mathrm{C}_{2}$ symmetry, and the two epoxy groups in the monomer are equal in reactivity. This symmetric character is responsible for producing a polymer consisting of a single constitutional unit. Therefore, it is interesting to elucidate the character of 1,2:5,6-dianhydrohexitol with $\mathrm{C}_{1}$ symmetry in cyclopolymerization. There are ten hexitols which contain two meso forms and four pairs of optical enantiomers. Two pairs of D- and L-isomers in mannitol and iditol are $\mathrm{C}_{2}$ symmetric and the other pairs are asymmetric. D-Glucitol is contained in the latter pairs and therefore 1,2:5,6-dianhydro-D-glucitol possesses two epoxy groups whose reactivities are nonequivalent.

This paper reports the cyclopolymerization of $1,2: 5,6$ dianhydro-3,4-di- $O$-methyl-D-glucitol (4) using cationic and anionic catalysts. The structures of the polymers (5) are discussed by comparing their ${ }^{13} \mathrm{C}$ NMR spectra with those of 2,5-anhydro-1,3,4,6-tetra- $O$-methyl-D-mannitol
(6), -L-iditol (7) and -D-glucitol (8) as model compounds. Polymer 5 prepared using $\mathrm{BF}_{3} \cdot \mathrm{OEt}_{2}$ was composed mainly of 2,5-anhydro-3,4-di- $O$-methyl-D-mannitol as the constitutional cyclic unit corresponding to 6 . On the other hand, polymer 5 prepared using $t$-BuOK contained two kind of cyclic units corresponding to 6 and 7 .

\section{EXPERIMENTAL}

\section{Measurements}

${ }^{1} \mathrm{H}$ and ${ }^{13} \mathrm{C}$ NMR spectra were recorded with JEOL JNM-EX270 and JNM-A400 II. Optical rotations were determined with a JASCO DIP-140 digital polarimeter. The molecular weight of polymers was measured by gel permeation chromatography (GPC) in tetrahydrofuran on a JASCO HPLC system equipped with three polystyrene gel columns (Shodex KF-804L). The numberaverage molecular weight $\left(M_{\mathrm{n}}\right)$ and molecular weight distribution $\left(M_{w} / M_{n}\right)$ were calculated on the basis of a polystyrene calibration. Thin layer chromatography was performed on silicagel $60 \mathrm{~F}_{254}(0.25$ and $2.0 \mathrm{~mm}$ thick, Merck).

\section{Materials}

Dichloromethane and nitroethane were distilled over calcium hydride. Toluene, tetrahydrofuran, and 1,4-dioxane were purified by the usual method and distilled from sodium-benzophenone. Borontrifluoride etherate $\left(\mathrm{BF}_{3} \cdot \mathrm{OEt}_{2}\right)$ and tin(IV) chloride $\left(\mathrm{SnCl}_{4}\right)$ were purified by distillation of commercial products under reduced pressure, and used as a solution in dry dichloromethane. Potassium tert-butoxide $(t-\mathrm{BuOK})$ was purified by sublimation under vacuum before use. 2,5-Anhydro-Dmannitol was purchased from Aldrich. 2,5-Anhydro-

$\dagger$ Research Fellow of the Japan Society for the Promotion of Science.

${ }^{\dagger+}$ To whom all correspondence should be addressed. 
1,3,4,6-tetra- $O$-methyl-D-glucitol (8) was synthesized from 1 by the same procedure in a previous report. ${ }^{15}$

\section{1,2: 5,6-Dianhydro-3,4-di-O-methyl-D-glucitol (4)}

Monomer 4 was prepared from D-glucitol according to the reported procedure. ${ }^{20} 4$ was distilled over $\mathrm{CaH}_{2}$ under reduced pressure before polymerization run. bp $0.3=72-73^{\circ} \mathrm{C} ;[\alpha]_{\mathrm{D}}-6.3^{\circ},[\alpha]_{577}-8.3^{\circ},[\alpha]_{546}-9.6^{\circ}$, $[\alpha]_{435}-15.6^{\circ}$, and $[\alpha]_{405}-18.8^{\circ}(c) 1.0$ in $\mathrm{CHCl}_{3}$ at $\left.22^{\circ} \mathrm{C}\right) ;{ }^{1} \mathrm{H}$ NMR $\left(400 \mathrm{~Hz}, \mathrm{CDCl}_{3}\right): \delta 3.57\left(\mathrm{~s}, \mathrm{CH}_{3} \mathrm{O}-\right.$, $3 \mathrm{H}), 3.45\left(\mathrm{~s}, \mathrm{CH}_{3} \mathrm{O}-, 3 \mathrm{H}\right), 3.10-3.21(\mathrm{~m}, 3 \mathrm{H}), 3.03(\mathrm{dd}$, $J=7.0$ and $3.3 \mathrm{~Hz}, 1 \mathrm{H}), 2.89(\mathrm{dd}, J=5.3$ and $3.7 \mathrm{~Hz}$, $1 \mathrm{H}), 2.78-2.81(\mathrm{~m}, 2 \mathrm{H})$, and $2.55 \mathrm{ppm}(\mathrm{dd}, J=4.8$ and $2.8 \mathrm{~Hz}, 1 \mathrm{H}) ;{ }^{13} \mathrm{C} \mathrm{NMR}\left(100 \mathrm{MHz}, \mathrm{CDCl}_{3}\right): \delta 83.71$ and $82.03(\mathrm{CH}), 59.77$ and $59.42\left(\mathrm{CH}_{3} \mathrm{O}-\right), 53.00$ and 50.74 (CH, epoxy), and 46.68 and $43.27 \mathrm{ppm}\left(\mathrm{CH}_{2}\right.$, epoxy).

\section{2,5-Anhydro-1,3,4,6-tetra-O-methyl-D-mannitol (6)}

To a stirred solution of 2,5-anhydro-D-mannitol (Aldrich, $40 \mathrm{mg}, 0.244 \mathrm{mmol}$ ) in dimethyl sulfoxide $(0.3 \mathrm{~mL})$ was simultaneously added a solution of sodium hydroxide $(0.11 \mathrm{~g}, 2.75 \mathrm{mmol})$ in water $(0.11 \mathrm{ml})$ and dimethyl sulfate $(0.12 \mathrm{ml}, 1.27 \mathrm{mmol})$ at a rate that the temperature of reaction mixture did not exceed $60^{\circ} \mathrm{C}$. Stirring was continued at this temperature for $30 \mathrm{~min}$. After standing overnight at room temperature, the mixture was poured into water, and extracted with chloroform. The extract was dried, and the residue purified by thin-layer chromatography with hexaneethyl acetate $(1: 1, R f 0.47)$ to give pure 6 as a colorless syrup $(31 \mathrm{mg}, 57.8 \%):[\alpha]_{\mathrm{D}}+36.3^{\circ},[\alpha]_{577}+38.3$, $[\alpha]_{546}+44.1^{\circ},[\alpha]_{435}+75.0^{\circ}$, and $[\alpha]_{405}+89.0^{\circ}(c 1.0$ in $\mathrm{CHCl}_{3}$ at $\left.23^{\circ} \mathrm{C}\right) ;{ }^{1} \mathrm{H} \mathrm{NMR}\left(270 \mathrm{MHz}, \mathrm{CDCl}_{3}\right): \delta 4.10$ $(\mathrm{ddd}, J=9.1,5.6$, and $1.3 \mathrm{~Hz}, \mathrm{H}-2,5,2 \mathrm{H}), 3.74(\mathrm{dd}$, $J=3.4$ and $1.3 \mathrm{~Hz}, \mathrm{H}-3,4,2 \mathrm{H}), 3.51(\mathrm{dd}, J=5.6$ and $1.3 \mathrm{~Hz}, \mathrm{H}-1,6,4 \mathrm{H})$, and $3.41 \mathrm{ppm}(\mathrm{s}, 4 \mathrm{MeO}, 12 \mathrm{H}) ;{ }^{13} \mathrm{C}$ NMR $\left(68 \mathrm{MHz}, \mathrm{CDCl}_{3}\right): \delta 86.70(\mathrm{C}-3,4), 81.30(\mathrm{C}-2$, 5), $72.78(\mathrm{C}-1,6), 59.21(2 \mathrm{MeO})$, and $57.52 \mathrm{ppm}(2 \mathrm{MeO})$. Anal. Calcd for $\mathrm{C}_{10} \mathrm{H}_{20} \mathrm{O}_{5}: \mathrm{C}, 54.53 \% ; \mathrm{H}, 9.15 \%$. Found C, $54.28 \%$; H, $9.10 \%$.

\section{2,5-Anhydro-1,3,4,6-tetra-O-methyl-L-iditol (7)}

2,5-Anhydro-L-iditol $(40 \mathrm{mg}, 0.244 \mathrm{mmol})$, prepared according to the method of Bock et al., ${ }^{21}$ in dimethyl sulfoxide $(0.3 \mathrm{ml})$ was treated with a solution of sodium hydroxide $(0.11 \mathrm{~g}, 2.75 \mathrm{mmol})$ in water $(0.11 \mathrm{ml})$ and dimethyl sulfate $(0.12 \mathrm{ml}, 1.27 \mathrm{mmol})$ as described for $\mathbf{5}$, to give, after thin-layer chromatography with hexaneethyl acetate $(1: 1, R f 0.45)$, pure 7 as a colorless syrup $(37.3 \mathrm{mg}, 69.6 \%):[\alpha]_{\mathrm{D}}+7.1^{\circ},[\alpha]_{577}+7.2^{\circ},[\alpha]_{546}$ $+8.6^{\circ},[\alpha]_{435}+17.9^{\circ}$, and $[\alpha]_{405}+22.6^{\circ}$ (c 1.0 in $\mathrm{CHCl}_{3}$ at $\left.23^{\circ} \mathrm{C}\right) ;{ }^{1} \mathrm{H}$ NMR $\left(270 \mathrm{MHz}, \mathrm{CDCl}_{3}\right): \delta 4.26$ $4.20(\mathrm{~m}, \mathrm{H}-2,5,2 \mathrm{H}), 3.80(\mathrm{dd}, J=5.0$ and $1.3 \mathrm{~Hz}, \mathrm{H}-3$, 4, $2 \mathrm{H}$ ), 3.55 (dd, $J=6.1$ and $4.1 \mathrm{~Hz}, \mathrm{H}-1,6,4 \mathrm{H}), 3.41$ (s, $2 \mathrm{MeO}, 6 \mathrm{H})$, and $3.38 \mathrm{ppm}(\mathrm{s}, 2 \mathrm{MeO}, 6 \mathrm{H}) ;{ }^{13} \mathrm{C} \mathrm{NMR}$ $\left(68 \mathrm{MHz}, \mathrm{CDCl}_{3}\right): \delta 83.29(\mathrm{C}-3,4), 78.53(\mathrm{C}-2,5), 70.71$ $(\mathrm{C}-1,6), 59.14(2 \mathrm{MeO})$, and $58.03 \mathrm{ppm}(2 \mathrm{MeO})$. Anal. Calcd for $\mathrm{C}_{10} \mathrm{H}_{20} \mathrm{O}_{5}: \mathrm{C}, 54.53 \% ; \mathrm{H}, 9.15 \%$. Found $\mathrm{C}$, $54.91 \% ; \mathrm{H}, 8.77 \%$.

\section{Cationic Polymerization}

A typical polymerization procedure is as follows: Monomer $4(0.5 \mathrm{~g}, 2.87 \mathrm{mmol})$ was dissolved in dry
$\mathrm{CH}_{2} \mathrm{Cl}_{2}(5.74 \mathrm{ml})$, and $\mathrm{BF}_{3} \cdot \mathrm{OEt}_{2}$ in $\mathrm{CH}_{2} \mathrm{Cl}_{2}(39.1 \mu \mathrm{l}$ in $0.73 \mathrm{~mol} \cdot 1^{-1}, 0.0285 \mathrm{mmol}$ ) was added by a microsyringe at $0^{\circ} \mathrm{C}$. After $24 \mathrm{~h}$, the reaction mixture was poured into a excess methanol containing a drop of aqueous ammonia, and the entire solution was evaporated under reduced pressure. The residue was washed with $n$-hexane several times and dried under vacuum to give the polymer $(355 \mathrm{mg}, 70.9 \%)$. The number-averaged molecular weight $\left(M_{n}\right)$ and molecular weight distribution $\left(M_{w} / M_{n}\right)$ were 3770 and 3.77 , respectively. $[\alpha]_{\mathrm{D}}+43.9^{\circ},[\alpha]_{577}$ $+44.9^{\circ},[\alpha]_{546}+50.2^{\circ},[\alpha]_{435}+80.3^{\circ}$, and $[\alpha]_{405}$ $+93.9^{\circ}\left(c 1.0\right.$ in $\mathrm{CHCl}_{3}$ at $\left.22^{\circ} \mathrm{C}\right) ;{ }^{13} \mathrm{C} \mathrm{NMR}(100 \mathrm{MHz}$, $\left.\mathrm{CDCl}_{3}\right): \delta 86.77(\mathrm{CH}), 81.51(\mathrm{CH}), 71.59\left(\mathrm{CH}_{2}\right)$, and $57.56 \mathrm{ppm}\left(\mathrm{CH}_{3}\right)$.

Anionic Polymerization A typical polymerization procedure is as follows: Polymerization was carried out in an $\mathrm{H}$-shaped glass ampoule. $t$-BuOK $(12.2 \mathrm{mg}$, $0.11 \mathrm{mmol})$ and dry tetrahydrofuran (THF) $(2.0 \mathrm{ml})$ were added to one side of the ampoule, and $4(0.355 \mathrm{~g}, 2.04$ mmol) was added to the other side under a nitrogen atmosphere. After sealing under vacuum, the monomer and catalyst solution were mixed at $60^{\circ} \mathrm{C}$. After $48 \mathrm{~h}$, the reaction mixture was poured into a excess methanol containing a drop of $0.1 \mathrm{~N}$ hydrochloric acid, and the system was evaporated under reduced pressure. The residue was treated as described for the cationic polymerization to give the polymer $(0.282 \mathrm{~g}, 79.5 \%)$. The $M_{n}$ and $M_{w} / M_{n}$ were 4960 and 1.71 , respectively. $[\alpha]_{577}$ $+73.4^{\circ},[\alpha]_{546}+81.4^{\circ},[\alpha]_{435}+133.0^{\circ}$, and $[\alpha]_{405}$ $+156.2^{\circ}\left(c 1.0\right.$ in $\mathrm{CHCl}_{3}$ at $\left.22^{\circ} \mathrm{C}\right) ;{ }^{13} \mathrm{C} \mathrm{NMR}(68 \mathrm{MHz}$, $\left.\mathrm{CDCl}_{3}\right): \delta 86.72(\mathrm{CH}), 83.21(\mathrm{CH}), 81.43(\mathrm{CH}), 78.71$ $(\mathrm{CH}), 71.42\left(\mathrm{CH}_{2}\right), 69.35\left(\mathrm{CH}_{2}\right), 58.10\left(\mathrm{CH}_{3}\right)$, and $57.52 \mathrm{ppm}\left(\mathrm{CH}_{3}\right)$.

\section{RESULTS}

\section{Cyclopolymerization}

The polymerizations of 1,2:5,6-dianhydro-3,4-di- $O$ methyl-D-glucitol (4) using $\mathrm{BF}_{3} \cdot \mathrm{OEt}_{2}$ and $\mathrm{SnCl}_{4}$ proceeded homogeneously up to high conversion under the conditions. The result was shown in Table I. The obtained polymers were yellowish-brown semisolids, and soluble in chloroform, methanol, tetrahydrofuran, and water but insoluble in $n$-hexane, except that the po-

Table I. Cationic polymerization of 1,2:5,6-dianhydro3,4-di- $O$-methyl-D-glucitol (4) ${ }^{\mathrm{a}}$

\begin{tabular}{|c|c|c|c|c|c|}
\hline \multirow{2}{*}{ Catalyst } & \multirow{2}{*}{ Solvent } & Yield & \multirow{2}{*}{$M_{n}{ }^{\mathrm{b}}$} & \multirow{2}{*}{$M_{w} / M_{n}^{\mathrm{b}}$} & \multirow{2}{*}[\alpha]{$_{546}^{22}$} \\
\hline & & $\%$ & & & \\
\hline \multirow[t]{3}{*}{$\mathrm{BF}_{3} \cdot \mathrm{OEt}_{2}$} & $\mathrm{CH}_{2} \mathrm{Cl}_{2}$ & 70.9 & 3,770 & 3.77 & $+50.2^{\circ}$ \\
\hline & $\mathrm{C}_{6} \mathrm{H}_{5} \mathrm{CH}_{3}$ & $7.4^{\mathrm{d}}$ & 2,010 & 5.05 & $+52.6^{\circ}$ \\
\hline & $\mathrm{C}_{2} \mathrm{H}_{5} \mathrm{NO}_{2}$ & 81.8 & 3,340 & 3.68 & $+62.7^{\circ}$ \\
\hline \multirow[t]{3}{*}{$\mathrm{SnCl}_{4}$} & $\mathrm{CH}_{2} \mathrm{Cl}_{2}$ & 8.1 & 1,370 & 1.55 & $+40.6^{\circ}$ \\
\hline & $\mathrm{C}_{6} \mathrm{H}_{5} \mathrm{CH}_{3}$ & 5.2 & 1,430 & 1.61 & $+55.0^{\circ}$ \\
\hline & $\mathrm{C}_{2} \mathrm{H}_{5} \mathrm{NO}_{2}$ & 12.4 & 1,090 & 1.43 & $+61.9^{\circ}$ \\
\hline
\end{tabular}

${ }^{\mathrm{a}}[4]=0.5 \mathrm{moll}^{-1} ;[4] /[\mathrm{Cat}]=$.$100 ; temp, 0^{\circ} \mathrm{C}$; time, $24 \mathrm{~h} .{ }^{\mathrm{b}} \mathrm{Mea}-$ sured in THF by GPC using poly(styrene) as standard. ${ }^{c}$ Measured in $\mathrm{CHCl}_{3}(c=1.0)$. ${ }^{\mathrm{d}}$ Yield of the organic solvent-insoluble polymer was $14.5 \%$ 
Table II. Polymerization of 1,2:5,6-dianhydro-3,4-di$O$-methyl-D-glucitol (4) with $t$-BuOK ${ }^{\mathrm{a}}$

\begin{tabular}{lccccc}
\hline \multirow{2}{*}{ Solvent } & Yield & & & & \\
& \multicolumn{1}{c}{${ }^{\mathrm{b}}$} & $M_{n} / M_{n}{ }^{\mathrm{b}}$ & {$[\alpha]_{546}^{22}{ }^{\mathrm{c}}$} & $y / x^{\mathrm{d}}$ \\
& $\%$ & & & & \\
\hline 1,4-Dioxane & 79.4 & 5,510 & 1.59 & $+69.2^{\circ}$ & 1.5 \\
THF & 79.5 & 4,960 & 1.71 & $+81.4^{\circ}$ & 1.5 \\
$\mathrm{C}_{6} \mathrm{H}_{5} \mathrm{CH}_{3}$ & 88.0 & 4,530 & 1.48 & $+76.7^{\circ}$ & 1.3 \\
\hline
\end{tabular}

${ }^{\mathrm{a}}[4]=1.0 \mathrm{moll}^{-1} ;[4] /[t-\mathrm{BuOK}]=20 ;$ temp, $60^{\circ} \mathrm{C} ;$ time, $48 \mathrm{~h}$. ${ }^{\mathrm{b}}$ Measured in THF by GPC using poly(styrene) as standard. ${ }^{\mathrm{c}} \mathrm{Mea}-$ sured in $\mathrm{CHCl}_{3}(c=1.0)$. ${ }^{\mathrm{d}}$ Values determined by ${ }^{13} \mathrm{C}$ NMR using inverse gated spin decoupling. The area ratios of $\mathrm{C}-1, \mathrm{C}-2$, and $\mathrm{C}-3$ in 2,5-anhydro-3,4-di- $O$-methyl-L-iditol unit to those in -D-mannitol unit were estimated, respectively, and the values were avaraged.

lymerization using $\mathrm{BF}_{3} \cdot \mathrm{OEt}_{2}$ in toluene gave the organic solvent-insoluble polymer in a $14.5 \%$ yield together with the soluble polymer in a $7.4 \%$ yield. The yields and number-average molecular weights $\left(M_{n} \mathrm{~s}\right)$ for the polymers obtained in dichloromethane and nitroethane using $\mathrm{BF}_{3} \cdot \mathrm{OEt}_{2}$ were higher than those for the others. For the polymer in the system of $\mathrm{BF}_{3} \cdot \mathrm{OEt}_{2} / \mathrm{CH}_{2} \mathrm{Cl}_{2}$, the yield and $M_{n}$ were $71 \%$ and 3770 corresponding to the number-average degree of polymerization $(D P)$ of 22 , respectively.

Table II lists the results of the polymerization of 4 using $t$-BuOK. The polymerization systems were homogeneous and gradually turned brown. The resulting polymers were viscous liquids and soluble in organic solvents and water as in the case of those obtained using cationic initiators. $M_{n}$ s were 4530 to 5510 with an $M_{w} /$ $M_{n}$ value of $1.48-1.71$. Specific rotations $\left([\alpha]_{546}^{22}\right)$ were $+40.6^{\circ}$ to $+62.7^{\circ}$ for the polymers using $\mathrm{BF}_{3} \cdot \mathrm{OEt}_{2}$ and $\mathrm{SnCl}_{4}$, and $+69.2^{\circ}$ to $+81.4^{\circ}$ for those using $t$-BuOK $\left(c=1.0\right.$ in $\left.\mathrm{CHCl}_{3}\right)$. For both polymers, the specific rotation should be affected by the composition of constitutional units and the $M_{n}$, but this is an unresolved problem and further study is needed.

\section{Polymer Structure}

Figure 1 shows the ${ }^{1} \mathrm{H}$ NMR spectra of polymer 5 obtained using $\mathrm{BF}_{3} \cdot \mathrm{OEt}_{2}$ and $t$-BuOK. The characteristic signals in the range of 2.5 to $3.2 \mathrm{ppm}$ due to the epoxy groups completely disappeared; therefore, the extent of cyclization was $100 \%$, i.e., both polymerizations proceeded according to a cyclopolymerization mechanism leading to the polymers with cyclic constitutional repeating units. In both spectra, an apparent difference was observed in the regions of $3.4-4.4 \mathrm{ppm}$, which suggests differences in stereochemistry between the polymers from the systems of $\mathrm{BF}_{3} \cdot \mathrm{OEt}_{2}$ and $t$ - $\mathrm{BuOK}$.

For the cyclopolymerizations of $\mathbf{1}$ and $\mathbf{2}$, the cyclic constitutional unit in polymer $\mathbf{3}$ was a five-membered ring, as shown in Scheme $1 .{ }^{15}$ In order to confirm the cyclic structural unit in polymer 5 , the ${ }^{13} \mathrm{C}$ NMR spectra of the polymers were compared with those of three 2,5-anhydrohexitols, i.e., 2,5-anhydro-1,3,4,6-tetra- $O$ methyl-D-mannitol (6), -L-iditol (7), and -D-glucitol (8). Table III summarizes the ${ }^{13} \mathrm{C}$ NMR chemical shifts of these compounds. Although ten peaks were present in the spectrum of $\mathbf{8}$, only five peaks were found in each of the spectra, 6 and 7 , which reflects the $\mathrm{C}_{2}$ symmetry of
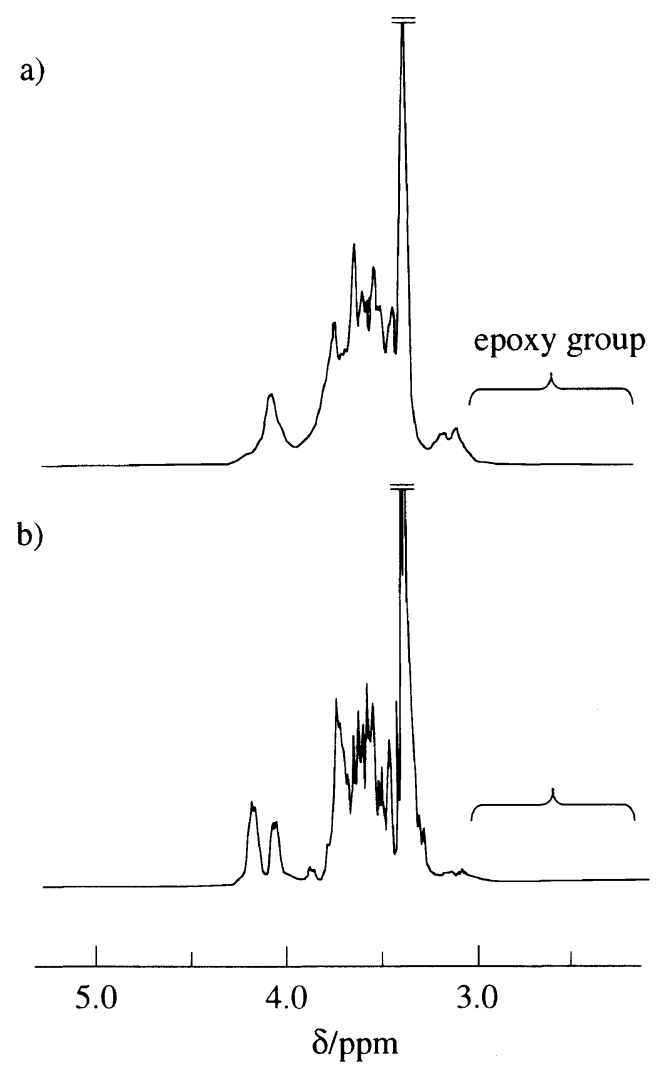

Figure 1. ${ }^{1} \mathrm{H}$ NMR spectra of polymers prepared from 1,2:5,6-dianhydro-3,4-di- $O$-methyl-D-glucitol (4) using (a) $\mathrm{BF}_{3} \cdot \mathrm{OEt}_{2}$ in dichloromethane and (b) $t$-BuOK in toluene.

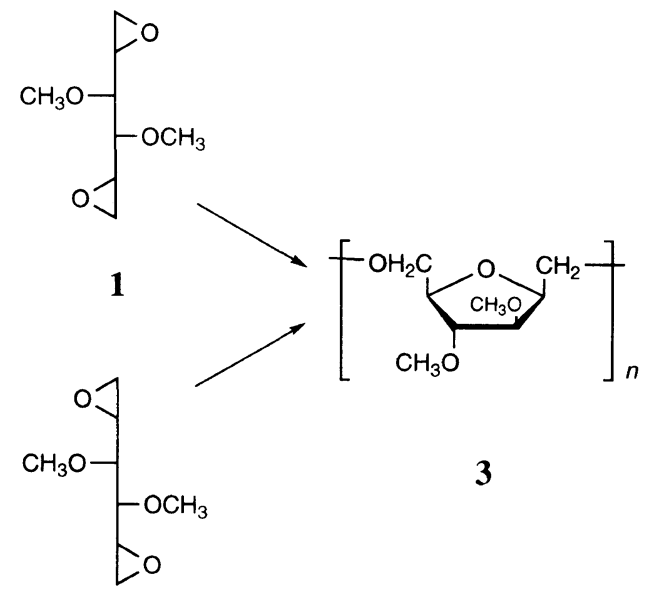

2

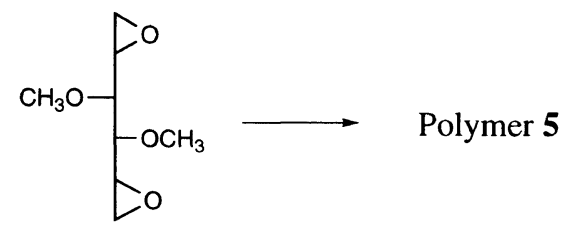

4

Scheme 1.

compounds 6 and 7.

The ${ }^{13} \mathrm{C}$ NMR spectra also were apparently different between the polymers in the systems of $\mathrm{BF}_{3} \cdot \mathrm{OEt}_{2}$ and 
Table III. ${ }^{13} \mathrm{C}$ NMR chemical shifts of 2,5-anhydro-1,3,4,6tetra- $O$-methyl-D-mannitol (6), -L-iditol (7), and -D-glucitol (8)

\begin{tabular}{lcccccccc}
\hline & $\mathrm{C}-1$ & $\mathrm{C}-2$ & $\mathrm{C}-3$ & $\mathrm{C}-4$ & $\mathrm{C}-5$ & $\mathrm{C}-6$ & $3,4-O-\mathrm{CH}_{3}$ & $1,6-O-\mathrm{CH}_{3}$ \\
\hline \multicolumn{7}{c}{$\delta / \mathrm{ppm}$} \\
\hline $\mathbf{6}$ & 72.78 & 81.30 & 86.70 & 86.70 & 81.30 & 72.78 & 57.52 & 59.21 \\
7 & 70.71 & 78.53 & 83.29 & 83.29 & 78.53 & 70.71 & 58.03 & 59.14 \\
$\mathbf{8}$ & 73.15 & 82.26 & 85.69 & 84.75 & 79.83 & 70.66 & $57.35,57.42$ & $59.19,59.25$
\end{tabular}

${ }^{\text {a }}$ All values were measured in $\mathrm{CDCl}_{3}$ solution using tetramethylsilane as a reference.

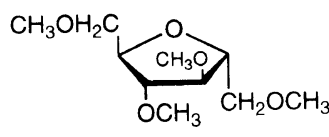

6

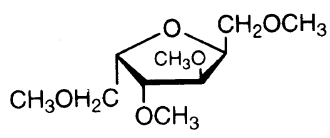

7

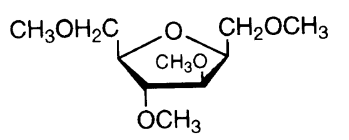

8

Chart

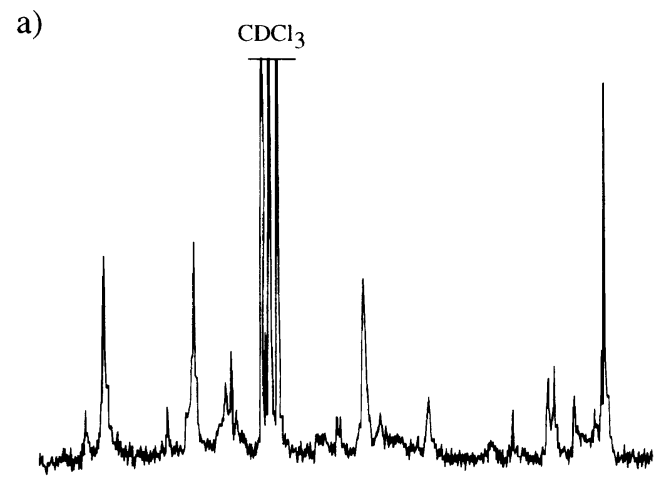

b)

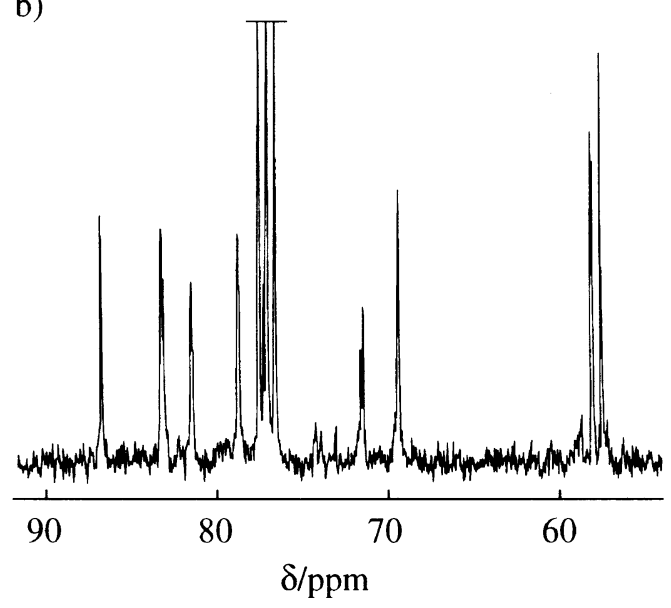

Figure 2. ${ }^{13} \mathrm{C}$ NMR spectra of the polymers prepared from $1,2: 5,6$ dianhydro-3,4-di-O-methyl-D-glucitol (4) using (a) $\mathrm{BF}_{3} \cdot \mathrm{OEt}_{2}$ in dichloromethane and (b) $t$-BuOK in toluene.

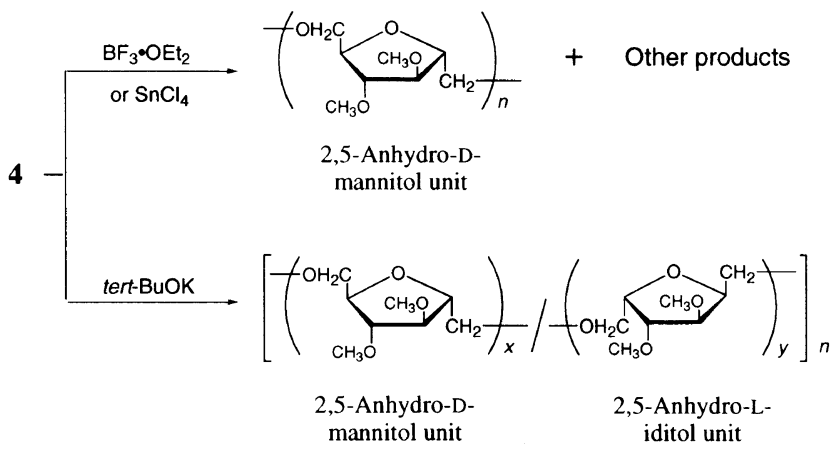

Scheme 2.

$t$-BuOK, as shown in Figure 2. For the polymer using $\mathrm{BF}_{3} \cdot \mathrm{OEt}_{2}$, four main peaks at $86.77,81.51,71.59$, and $57.56 \mathrm{ppm}$ were assigned to the methine, methine, methylene, and methoxy carbons, respectively, and thus the polymer resembles $\mathbf{6}$ very closely in chemical shifts. The structure of polymer 5 using cationic catalysts should thereby be mainly 2,5 -anhydro-3,4-di- $O$-methylD-mannitol as the five-membered constitutional unit. Several weak absorptions found in the spectrum of the polymer (Figure 2a), however, indicate that there might exist six- and seven-membered rings as minor constitutional units together with the 2,5-anhydro-3,4-di- $O$ methyl-D-mannitol as major unit.

The spectrum of the polymer using $t$-BuOK consists of eight main peaks in which four peaks at 86.72 (methine), 81.43 (methine), 71.58 (methylene), and $57.52 \mathrm{ppm}$ (methoxy) are similar to those assigned to the carbons of C-3,4, C-2,5, C-1,6, and the methoxy groups for 6, respectively, and the other four peaks at 83.21 (methine), 78.71 (methine), 69.35 (methylene), and $58.10 \mathrm{ppm}$ (methyl) are close to those for 7 in chemical shifts. Therefore, the polymer obtained by anionic polymerization consists of two cyclic repeating units, 2,5-anhydro-3,4-di- $O$-methyl-D-mannitol and -L-iditol, as seen in Scheme 2. The peaks observed in Figure $2 b$ were slightly broad and some split into two bands. This should be caused by the differences in sequences of the two five-membered repeating units, because the crosspeaks corresponding to six- or seven-membered ring units could not be observed in the ${ }^{13} \mathrm{C}-{ }^{1} \mathrm{H}$ COSY measurement. The ratio of 2,5-anhydro-3,4-di- $O$-methyl-Liditol units to -D-mannitol units $(y / x)$ in the polymer was estimated by ${ }^{13} \mathrm{C}$ NMR using the inverse gated spin decoupling technique and was indicated in Table II. For the anionic cyclopolymerization in 1,4-dioxane, the ratio $y / x$ was 1.5 , which means that the polymerization was favorable for forming 2,5-anhydro-3,4-di- $O$-methyl-Liditol unit.

\section{DISCUSSION}

For both polymers prepared by the cationic and anionic polymerizations of $\mathbf{4}$, absorption due to 2,5-anhydro1,3,4,6-tetra- $O$-methyl-D-glucitol (8) was not observed in the ${ }^{13} \mathrm{C}$ NMR spectra. A absence of 8 units was also confirmed by ${ }^{13} \mathrm{C}-{ }^{1} \mathrm{H}$ COSY. This indicates that these polymerizations would proceed through the inversion of the configuration at the $\mathrm{C}-2$ or $\mathrm{C}-5$ of 4 , i.e., through the $S_{\mathrm{N}} 2$ reaction. 
For the cationic polymerization of monosubstituted epoxides through the $S_{\mathrm{N}} 2$-type mechanism, the configuration of the asymmetric carbon atom is inverted due to the ring opening at the $\mathrm{CH}-\mathrm{O}$ bond ( $\alpha$-scission) and retention by the $\mathrm{CH}_{2}-\mathrm{O}$ bond ( $\beta$-scission). The anionic polymerization proceeds exclusively through the $\beta$ scission. In monomer $\mathbf{4}$, epoxides at the 1,2- and 5,6positions are different in reactivity, because of their different stereochemistry. Therefore, the possible cyclic units in polymer $\mathbf{5}$ may be considered eight stereoisomers $(5 \mathbf{a}-\mathbf{h})$ formed through the $S_{\mathrm{N}} 2$-type mechanism, as shown in Scheme 3, where $\alpha_{12}$ and $\beta_{12}$, and $\alpha_{56}$ and $\beta_{56}$ represent $\alpha$ - and $\beta$-scissions in the 1,2- and 5,6-epoxides, respectively. In the cyclopolymerization of $\mathbf{4}$, the intermolecular reaction and intramolecular cyclization through $\alpha_{12}, \alpha_{56^{-}}, \alpha_{56}, \alpha_{12^{-}}, \beta_{12}, \beta_{56^{-}}$, and $\beta_{56}, \beta_{12^{-}}$scissions of the two epoxides in the molecule form the 6membered rings $\mathbf{5 a}, \mathbf{5 b}, \mathbf{5 g}$, and $\mathbf{5 h}$, respectively; whereas, $\beta_{12}, \alpha_{56^{-}}$and $\beta_{56}, \alpha_{12}$-scissions lead to the formation of the 5-membered rings $5 \mathbf{e}$ and $\mathbf{5 f}$, and $\alpha_{12}, \beta_{56^{-}}$and $\alpha_{56}, \beta_{12^{-}}$scissions to that of the 7 -membered rings $5 \mathrm{c}$ and $5 \mathbf{d}$.

Because the ${ }^{13} \mathrm{C}$ NMR spectrum of polymer $5 \mathrm{ob}-$ tained using $\mathrm{BF}_{3} \cdot \mathrm{OEt}_{2}$ showed that the cyclic repeating unit consists mainly of 2,5-anhydro-3,4-di- $O$-methyl-Dmannitol 5f, the cationic polymerization of 4 is concluded to involve $\beta_{56}, \alpha_{12}$-scission selectively. In intramolecular cyclization, the $\alpha$-carbon of the 1,2 -epoxide moiety having oxonium ion form is attacked by the oxygen atom of the 5,6-epoxide, and the resulting bicyclic oxonium ion is subsequently attacked at the $\beta$-carbon by a monomer in the intermolecular reaction as shown in Scheme 4. The $\alpha$-scission of the 1,2-epoxide moiety leads to inversion of the configuration $(S \rightarrow R)$, whereas the $\beta$-scission of the 5,6-epoxide moiety causes retention of the configuration $(R \rightarrow R)$. Thus, the formation of 2,5-anhydro-3,4-di- $O$-methyl-D-mannitol $\mathbf{5 f}$ results from the regio- and stereoselective mechanism. It is worth noting that the ring-opening mode of the epoxide is different for the inter- and intramolecular reactions.

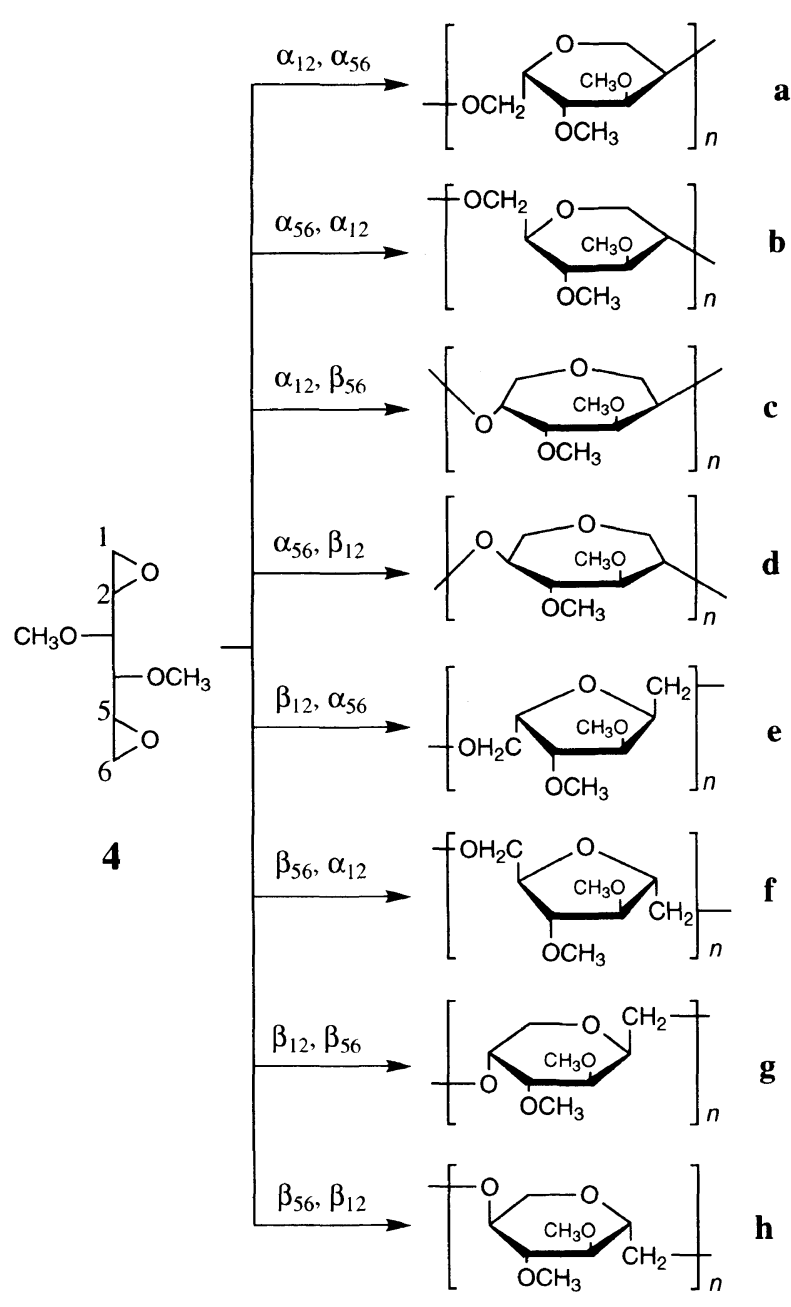

5

Scheme $3^{\text {a }}$.

${ }^{a}$ Former and latter symbols correspond to intermolecular and intramolecular scissions, respectively.
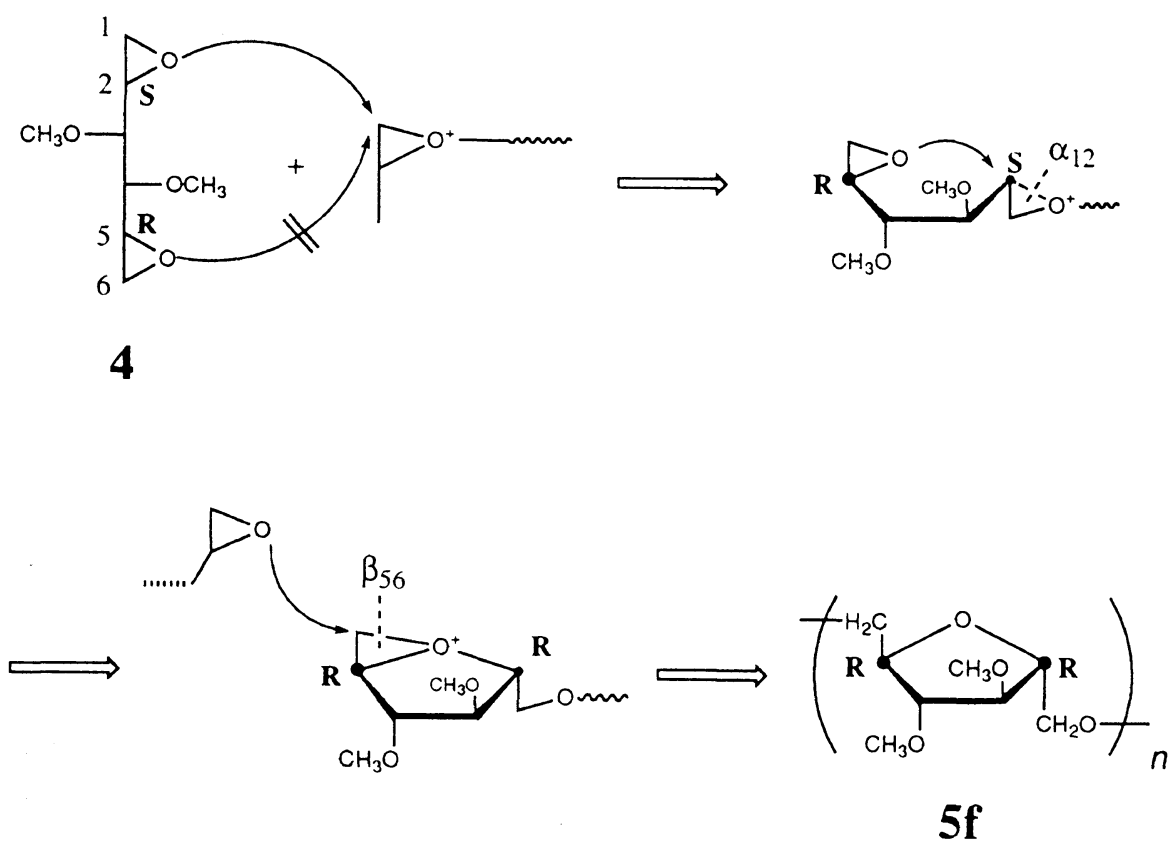

Scheme 4. 

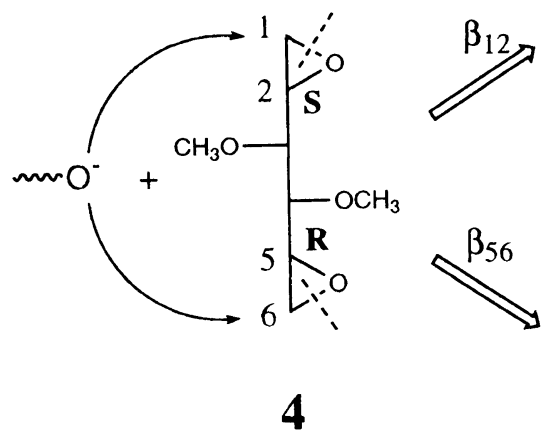
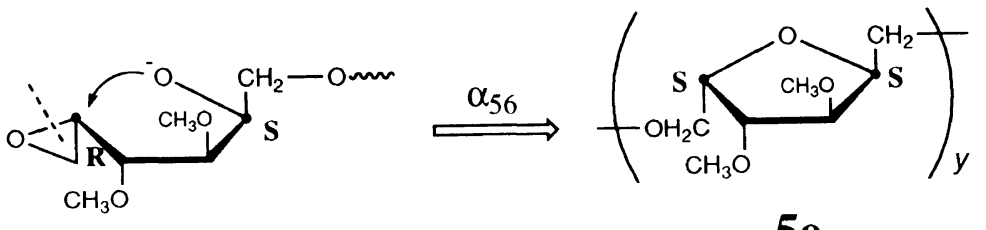

$5 e$

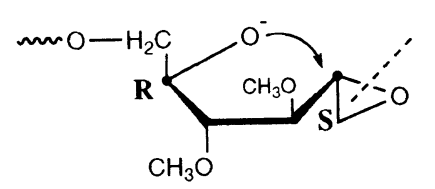

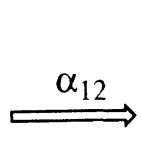

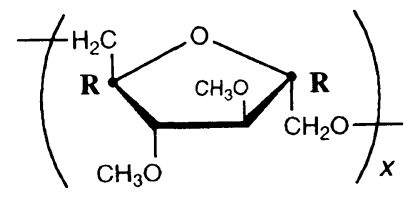

$\mathbf{5 f}$

Scheme 5 .

The former reaction takes place preferentially at the 1,2-epoxide moiety as a nucleophile between the two epoxide moieties in the monomer.

The anionic cyclopolymerization of $\mathbf{4}$ produced a polymer consisting of two cyclic repeating units, 2,5anhydro-3,4-di- $O$-methyl-D-mannitol $5 \mathbf{e}$ and L-iditol $\mathbf{5 f}$. In the polymerization, intermolecular reaction through $\beta$-scission is established with retention of configuration, but the intramolecular cyclization through $\alpha$-scission occurred with inversion. In $\beta_{12}, \alpha_{56}$-scission, (1) retention at C-2 $(S \rightarrow S)$ and inversion at C-5 $(R \rightarrow S)$ to form cyclic unit 5e with $S, S$-configuration, and the $\beta_{56}, \alpha_{12}$-scission is the opposite, (2) retention at the $\mathrm{C}-5(R \rightarrow R)$ and inversion at the $\mathrm{C}-2(S \rightarrow R)$ to form cyclic unit $\mathbf{5 f}$ with $R, R$-configuration, as shown in Scheme 5 . The two processes competitively take place to produce a polymer consisting of 2,5-anhydro-3,4-di- $O$-methyl-L-iditol $\mathbf{5 f}$ and -D-mannitol 5e with a ratio $(y / x)$ of about 1.5 . Although involving two processes, the polymerization proceeds through a regio- and stereoselective mechanism in each process. The intermolecular reaction takes place selectively at the 1,2-epoxide moiety rather than the 5,6 -epoxide moiety of monomer in the anionic polymerization. The alternating process of $\beta$-scission in the intermolecular reaction and $\alpha$-scission in the intramolecular cyclization is the most striking aspect in the anionic polymerization. The superiority of $\alpha$-scission in the intramolecular cyclization to form the five-membered rings in both polymerizations can be explained by the Baldwin rule which is generally suited to ring closure on the basis of stereoelectronic effect. ${ }^{22,23}$

The intramolecular cyclization of $\mathbf{4}$ was regio- and stereoselective to form five-membered repeating units, though the presence of other cyclized units for the cationic polymerization and the formation of two 2,5-anhydrohexitol units for the anionic polymerization. For intermolecular propagation, the 1,2-epoxy group of 4 predominantly reacted with the growing chain-end, which should be caused by differences in the stereochemistry of the transition state between the 1,2-epoxy and 5,6-epoxy groups. Therefore, to elucidate these phenomena, we are currently calculating the energy of transition by ab initio and semi-empirical calculations.

\section{CONCLUSIONS}

The polymerizations of 1,2:5,6-dianhydro-3,4-di- $O$ methyl-D-glucitol were carried out using cationic and anionic catalysts. The polymerizations proceeded through the cyclopolymerization mechanism leading to polymers with cyclic constitutional units. The cationic cyclopolymerization yielded a polymer consisting mainly of 2,5anhydro-3,4-di- $O$-methyl-D-mannitol units. The anionic polymerization involves two processes to yield a polymer consisting of 2,5-anhydro-3,4-di- $O$-methyl-D-mannitol and L-iditol units. The intermolecular reaction exclusively selected the 1,2-epoxide moiety of monomer in the cationic polymerization but slightly favored the 5,6 -epoxide moiety in the anionic polymerization. The intra- and intermolecular reactions introduced $\alpha$ - and $\beta$-scissions of the epoxides with inversion and retention of the configuration at the $\alpha$-carbon of epoxide moiety, respectively, in both polymerizations which are regioand stereoselective.

Acknowledgment. This work was supported by a Research Fellowship of the Japan Society for the Promotion of Science for Young Scientists.

\section{REFERENCES}

1. V. V. Korshak, D. P. Golova, V. A. Sergeev, N. M. Merlis, and R. Y. Shneer, Vysokomol. Soedin. Ser. III, 3, 477 (1961).

2. C.-C. Tu and C. Schuerch, Polym. Lett., 1, 163 (1963).

3. H. Sumitomo, M. Okada, and Y. Hibino, J. Polym. Sci., Polym. Lett. Ed., 10, 871 (1972).

4. F. Micheel, O. Brodde, and K. Reinking, Justus Liebigs Ann. Chem., 124 (1974).

5. C. Schuerch, Acc. Chem. Res., 6, 184 (1973).

6. T. Uryu, K. Kitano, H. Tachikawa, K. Ito, and K. Matsuzaki, Makromol. Chem., 179, 1773 (1978).

7. T. Uryu, Y. Koyama, and K. Matsuzaki, J. Polym. Sci., Polym. Lett. Ed., 17, 673 (1979).

8. H. Yamaguchi and C. Schuerch, Carbohydr. Res., 81, 192 (1980)

9. C. Schuerch, Adv. Carbohydr. Chem. Biochem., 39, 157 (1981).

10. T. Uryu, K. Kitano, K. Ito, J. Yamanouchi, and K. Matsuzaki, 
Macromolecules, 14, 1 (1981).

11. T. Uryu, J. Yamanouchi, T. Kato, S. Higuchi, and K. Matsuzaki, J. Am. Chem. Soc., 105, 6865 (1983).

12. H. Hashimoto, T. Kakuchi, and K. Yokota, J. Org. Chem., 56 , 6471 (1991).

13. T. Kakuchi, T. Satoh, S. Umeda, H. Hashimoto, and K. Yokota, Macromolecules, 28, 4062 (1995).

14. T. Kakuchi, S. Umeda, T. Satoh, H. Hashimoto, and K. Yokota, J. Macromol. Sci., Pure and Appl. Chem., A32, 1007 (1995).

15. T. Kakuchi, T. Satoh, S. Umeda, H. Hashimoto, and K. Yokota, Macromolecules, 28, 5643 (1995).

16. T. Satoh, T. Hatakeyama, S. Umeda, K. Yokota, and T. Kakuchi, Macromolecules, in press.
17. T. Satoh, K. Yokota, and T. Kakuchi, Macromolecules, 28, 4762 (1995).

18. K. Yokota, O. Haba, T. Satoh, and T. Kakuchi, Macromol. Chem. Phys., 196, 2383 (1995).

19. T. Kakuchi, T. Satoh, J. Mata, S. Umeda, H. Hashimoto, and K. Yokota, J. Macromol. Sci., Pure and Appl. Chem., A33(3), 325 (1996)

20. J. Kuszmann, Carbohydr. Res., 71, 123 (1979).

21. K. Bock, C. Pedersen, and H. Thogersen, Acta Chem. Scand., B35, 441 (1981)

22. J. E. Baldwin, J. Chem. Soc., Chem. Commun., 734 (1976).

23. G. Stork and J. F. Cohen, J. Am. Chem. Soc., 96, 5270 (1974). 